\title{
Theoretical Investigation of Energetic and its Effect on Cd-Hg Amalgam
}

\author{
I. Koirala ${ }^{12^{*}}$, B. P. Singh ${ }^{1}$, I. S. Jha ${ }^{3}$ A. K. Mallik ${ }^{3}$ \\ ${ }^{1}$ University Department of Physics, T.M. Bhagalpur University, Bhagalpur, India \\ ${ }^{2}$ Central Department of Physics, Tribhuvan University, Kirtipur, Nepal \\ ${ }^{3}$ M.M.A.M. Campus, Biratnagar, Tribhuvan University, Nepal \\ *Correspondence to: ikphysicstu@gmail.com
}

\begin{abstract}
The observed anomaly in properties of mixing of $\mathrm{Cd}$-Hg alloys in the molten state is successfully explained on the basis of the quasi-lattice model. The thermodynamic functions such as free energy of mixing, heat of mixing, entropy of mixing and chemical activity of the constituent atom of the alloys and microscopic functions like concentration-concentration fluctuation in long wavelength limit and Warren-Cowley short range order parameter of the alloys have been computed within the frame work of presented model. Most of the computed values are in good agreement with the experimental data. The pair-wise interaction energies between the species of the melt are found to depend considerably on temperature. Theoretical analysis suggests that hetero-coordination leading to the formation of complex $\mathrm{Cd}_{2} \mathrm{Hg}$ is likely to exist but is of weakly interacting in nature.
\end{abstract}

Keywords: Hetero-coordination; chemical activity; entropy; pair-wise interaction energy.

\section{Introduction}

Liquid alloys display a remarkable variety of local chemical order. The knowledge of mixing properties of liquid alloys is necessary for the design and development of industrial materials for high temperature application [Koirala et al., 2014]. Cadmium alloys have been widely used in fabricating solid state electronic components. Cadmium-mercury amalgam is used in Weston cell to produce a highly stable voltage. It is very difficult to conduct diffraction experiment on cadmium metal because of its highly reactive nature. Therefore theoretical investigation giving mixing properties of cadmium alloys are highly desirable. There has been considerable interest of theoreticians to explain the concentration dependent asymmetry in the properties of mixing of binary liquid alloys and hence to extract additional structural or microscopic information. Present day, various theoretical models [Prasad et al.,1991,1998; Singh et al., 1990,1992; Anusionwuetal.,1998; Novakovic et al.,2010; Akinlade et al., 2002; Jha et al., 2014; Guggenheim, 1952]. have been focused to study of the alloying behavior of alloys in the molten state. In the present investigation, the Quasilattice model [Bhatia \& Singh,1992; Bhatia \& Hargoov, 1974] has been used to estimate the thermodynamic and microscopic properties of the alloys at $600 \mathrm{~K}$ assuming $\mathrm{Cd}_{2} \mathrm{Hg}$ complex in the melt. Thermodynamic properties provide information on the interaction, stability and 
bonding strength among the constituent atoms in the alloys. The free energy of mixing, heat of mixing, entropy of mixing and activity of the species of the alloys are nearly symmetrical but concentration- concentration fluctuation at long wavelength limit and chemical short range order parameter are asymmetrical around equiatomic composition [Hultgren et al., 1973]. The microscopic properties are useful in obtaining the microscopic information on structure of molten alloys. The size factor $\left(\mathrm{V}_{\mathrm{Hg}} / \mathrm{V}_{\mathrm{Cd}}=\right.$ 1.14 , where $\mathrm{V}$ is atomic volume) and electronegativity $\left(\mathrm{E}_{\mathrm{Hg}}-\mathrm{E}_{\mathrm{Cd}}=0.31\right)$ are not so large to account for the anomalous behavior observed in the properties of mixing of $\mathrm{Cd}-\mathrm{Hg}$ liquid alloys [Singh \& Sommer, 1992]. Therefore, it is expected that concentration dependent anomaly arises due to energy effects.

\section{Methodology}

The present work is purely theoretical in nature and the following method are used for our investigations:

In present work, we use a quasi-lattice model to understand the mixing properties of simple binary liquid alloys with respect to concentration. In this model a grand partition function is constructed to deduce the relations for thermodynamic and microscopic functions. The quasi-lattice model is applicable for binary liquid alloys, which in solid or liquid state form a chemical compound at one or more well defined chemical composition and the complexes or the privileged group of atoms exist in the molten state. In this model, it is assumed that the energy of a given nearest neighbor bond is different if it belongs to the complex than if it does not. The model envisages the existence of chemical complexes $\mathrm{A}_{\mathrm{m}} \mathrm{B}_{\mathrm{n}}$, where $\mathrm{A}$ and $\mathrm{B}$ are the constituent species of the alloys and $\mathrm{m}$ and $\mathrm{n}$ are the small integers:

$$
\mathrm{mA}+\mathrm{nB}=\mathrm{A}_{\mathrm{m}} \mathrm{B}_{\mathrm{n}}
$$

With this consideration, grand partition function is solved and expression for excess free energy of mixing [Guggenheim, 1952] comes out to be

$$
\begin{aligned}
\mathrm{G}_{\mathrm{M}}^{\mathrm{XS}} & =\mathrm{Nk} \mathrm{B}_{\mathrm{B}} \mathrm{T} \int_{0}^{\mathrm{c}} \ln \gamma \mathrm{dc} \\
& =\mathrm{N}\left[\Phi \omega+\Phi_{\mathrm{AB}} \Delta \omega_{\mathrm{AB}}+\Phi_{\mathrm{AA}} \Delta \omega_{\mathrm{AA}}+\Phi_{\mathrm{BB}} \Delta \omega_{\mathrm{BB}}\right]
\end{aligned}
$$

Where $\mathrm{N}$ is the total number of the atoms in the alloys; $\mathrm{k}_{\mathrm{B}}$, the Boltzmann constant; $\mathrm{T}$, absolute temperature; $\gamma$, ratio of the activity coefficient of atom $\mathrm{A}$ to $\mathrm{B}$; $\mathrm{c}$, the concentration of atom $\mathrm{A}$; $\omega$ 's are the ordering energies; $\Phi=\mathrm{c}(1-\mathrm{c})$ and $\Phi_{\mathrm{ij}}(\mathrm{i}, \mathrm{j}=\mathrm{A}, \mathrm{B})$ are the simple polynomials in $\mathrm{c}$ depending on the values of $m$ and $n$, which is given by

$$
\begin{aligned}
k_{B} T \Phi_{m, n}= & =\Delta \omega_{A B}[2 \beta((m+1, n)-2 \beta(m, n+1)+\beta(2 m-1,2 n)+\beta(2 m, 2 n-1)]+ \\
& \Delta \omega_{A A}[\beta(2 m-2,2 n+1)-2 \beta(m, n+1)]+\Delta \omega_{B B}[2 \beta(m+1, n)-\beta(2 m+1,2 n-2)]
\end{aligned}
$$

Where $\beta$ 's are the usual beta functions. The free energy of mixing of a complex forming binary liquid alloys is

$$
\begin{aligned}
G_{M} & \left.=G_{M}^{X S}+N k_{B} T[C \operatorname{lnc} c+(1-c)) n(1-c)\right] \\
& =R T\left[\Phi \frac{\theta}{k_{B} T}+\Phi_{A B} \frac{\Delta \omega_{A B}}{k_{B} T}+\Phi_{A A} \frac{\Delta \omega_{A A}}{k_{B} T}+\Phi_{B B} \frac{\Delta \omega_{B B}}{k_{B} T}+c \operatorname{lnc}+(1-c) \ln (1-c)\right]
\end{aligned}
$$

Where $\mathrm{R}$ is the universal molar constant. The heat of mixing is easily found out by using the standard thermodynamic relation:

$$
\begin{aligned}
& \frac{H_{M}}{R T}=\frac{G_{M}}{R T}-\frac{1}{R}\left(\frac{d G_{M}}{d T}\right)_{\mathbb{N}, P}
\end{aligned}
$$

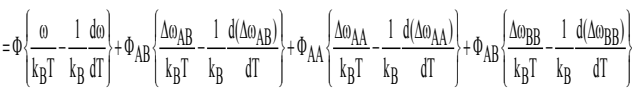


The standard thermodynamic relation for entropy of mixing is

$$
\frac{\mathrm{S}_{\mathrm{M}}}{\mathrm{R}}=\frac{\mathrm{H}_{\mathrm{M}}}{\mathrm{RT}}-\frac{\mathrm{G}_{\mathrm{M}}}{\mathrm{RT}}
$$

The chemical activity of the component atom in the alloys is deduced from standard relation $R T \ln a_{i}(i=A, B)=G_{M}+\left(1-c_{i}\right)\left(\partial G_{M} / \partial c_{i}\right)_{T, P, N}(6)$

$$
\begin{aligned}
\ln \mathrm{a}_{\mathrm{A}}= & \frac{\mathrm{G}_{\mathrm{M}}}{\mathrm{RT}}+\frac{1-\mathrm{c}}{\mathrm{k}_{\mathrm{B}} \mathrm{T}}\left[(1-2 \mathrm{c}) \omega+\Phi^{\prime}{ }_{\mathrm{AB}} \Delta \omega_{\mathrm{AB}}+\right. \\
& \left.\Phi^{\prime}{ }_{\mathrm{AA}} \Delta \omega_{\mathrm{AA}}+\Phi_{\mathrm{BB}}^{\prime} \Delta \omega_{\mathrm{BB}}+\ln (\mathrm{c} / 1-\mathrm{c})\right]
\end{aligned}
$$

Which are given by

$$
\begin{aligned}
\ln \mathrm{a}_{\mathrm{B}}= & \frac{\mathrm{G}_{\mathrm{M}}}{\mathrm{RT}}-\frac{\mathrm{c}}{\mathrm{k}_{\mathrm{B}} \mathrm{T}}\left[(1-2 \mathrm{c}) \omega+\Phi_{\mathrm{AB}}^{\prime} \Delta \omega_{\mathrm{AB}}+\right. \\
& \left.\Phi_{\mathrm{AA}}^{\prime} \Delta \omega_{\mathrm{AA}}+\Phi_{\mathrm{BB}}^{\prime} \Delta \omega_{\mathrm{BB}}+\ln (\mathrm{c} / 1-\mathrm{c})\right]
\end{aligned}
$$

Where $\Phi^{\prime}, \Phi^{\prime}{ }_{A B}, \Phi^{\prime}{ }_{A A}$ and $\Phi_{B B}^{\prime}$ are the derivatives of $\Phi, \Phi_{A B^{\prime}} \Phi_{A A}$ and $\Phi_{B B}$ respectively.

The concentration-concentration fluctuation in long wavelength limit [Bhatia and Thornton, 1970] for the alloy system is easily derived from standard relation

$$
\begin{aligned}
\mathrm{S}_{\mathrm{cc}}(0) & =\mathrm{RT}\left(\frac{\partial^{2} \mathrm{G}_{\mathrm{M}}}{\partial \mathrm{c}^{2}}\right)_{T, \mathrm{P}, \mathrm{N}}^{-1} \\
& =\frac{\mathrm{c}(1-\mathrm{c})}{1+\mathrm{c}(1-\mathrm{c})\left[-2 \frac{\omega}{\mathrm{k}_{\mathrm{B}} \mathrm{T}}+\Phi_{\mathrm{AB}}^{\prime \prime} \frac{\Delta \omega_{\mathrm{AB}}}{\mathrm{k}_{\mathrm{B}} T}+\Phi_{\mathrm{AA}}^{\prime \prime} \frac{\Delta \omega_{\mathrm{AA}}}{\mathrm{k}_{\mathrm{B}} T}+\Phi_{\mathrm{BB}}^{\prime \prime} \frac{\Delta \omega_{\mathrm{BB}}}{\mathrm{k}_{\mathrm{B}} T}\right]}
\end{aligned}
$$

Where $\Phi_{i j}^{\prime \prime}=\frac{\partial^{2} \Phi_{i j}}{\partial c^{2}}(i, j=A, B)$

For ideal mixing, concentrationconcentration fluctuations are usually computed from:

$$
\mathrm{S}_{\mathrm{cc}}^{\mathrm{id}}(0)=\mathrm{c}(1-\mathrm{c})
$$

The Warren-Cowley short range order parameter [Warren,1969; Cowley,1950] is related with the concentration-concentration fluctuation in long wavelength limit. Theoretical expression for the short range order parameter for the first neighbor shell is given by

$$
\alpha_{1}=\frac{S-1}{S(Z-1)+1}, S=\frac{S_{c c}(0)}{S_{c c}^{i d}(0)}
$$

where $\mathrm{z}$ is the coordination number, which is taken as 10 for our purposes.

For $\mathrm{Cd}_{2} \mathrm{Hg}$ system,

$\mathrm{A}=\mathrm{Cd}, \mathrm{B}=\mathrm{Hg}, \mathrm{m}=2, \mathrm{n}=1$

$$
\begin{aligned}
& \Phi_{\mathrm{AB}}=\frac{\mathrm{c}}{6}+\mathrm{c}^{2}-\frac{5 \mathrm{c}^{3}}{3}+ \\
& \Phi_{\mathrm{AA}}=-\frac{\mathrm{c}}{4}+\frac{\mathrm{c}^{2}}{2}-\frac{\mathrm{c}^{4}}{4} \\
& \Phi_{\mathrm{BB}}=0, \text { for } \mathrm{n}<2
\end{aligned}
$$

\section{Result and Discussion}

\subsection{Free energy of mixing}

The method of successive approximation is suitable for the determination of energy parameters used for the calculation of the free energy of mixing for $\mathrm{Cd}-\mathrm{Hg}$ liquid alloys. The parameters have been determined by using the experimental value of $\mathrm{G}_{\mathrm{M}}$ [Hultgren et al., 1973] in the concentration range from 0.1 to 0.9 . The best fit values of the parameter are

$$
\frac{\omega}{\mathrm{k}_{\mathrm{B}} \mathrm{T}}=-2.75, \frac{\Delta \omega_{\mathrm{AB}}}{\mathrm{k}_{\mathrm{B}} \mathrm{T}}=+1.12, \frac{\Delta \omega_{\mathrm{AA}}}{\mathrm{k}_{\mathrm{B}} \mathrm{T}}=-3.55, \frac{\Delta \omega_{\mathrm{BB}}}{\mathrm{k}_{\mathrm{B}} \mathrm{T}}=0
$$

The free energy of mixing $\left(\mathrm{G}_{\mathrm{M}}\right)$ for Cd$\mathrm{Hg}$ liquid alloys at $600 \mathrm{~K}$ is computed through Eq.(3). The plot of free energy of mixing verses concentration of cadmium is deposited in fig.1. The computed and experimental values of $\mathrm{G}_{\mathrm{M}}$ are in reasonable agreement throughout the concentration range from 0.1 to 0.9 of $\mathrm{Cd}$. Theoretical calculation of free energy of mixing for $\mathrm{Cd}-\mathrm{Hg}$ liquid alloys shows that 
the minimum value of free energy of mixing for $\mathrm{Cd}-\mathrm{Hg}$ is $-1.15018 \mathrm{RT}$ at $\mathrm{c}_{\mathrm{Cd}}=0.5$. This is excellent agreement with the experimental value [Hultgren et al., 1973]. Further, the negative values of all interaction energies suggest that $\mathrm{Cd}$ and $\mathrm{Hg}$ atoms are attracted to each other and consequently tendency of the system is found to be ordering (complex formation). The minimum value of free energy of mixing indicates that $\mathrm{Cd}$ $\mathrm{Hg}$ alloy in liquid state is moderately interacting system and hence, the tendency of compound formation is not strong in this alloy.

\subsection{Heat of mixing}

To determine the heat of mixing for liquid $\mathrm{Cd}-\mathrm{Hg}$ alloys, we need temperature derivatives of interaction energy parameters. The observed values of $\mathrm{H}_{\mathrm{M}}$ [Hultgren et al., 1973] are used to obtain the temperature derivatives by successive approximation method. The best fit values of these parameters are found to be

$\frac{1}{\mathrm{k}_{\mathrm{B}}} \frac{\partial \omega}{\partial \mathrm{T}}=1.42, \frac{1}{\mathrm{k}_{\mathrm{B}}} \frac{\partial\left(\Delta \omega_{\mathrm{AB}}\right)}{\partial \mathrm{T}}=-1.82, \frac{1}{\mathrm{k}_{\mathrm{B}}} \frac{\partial\left(\Delta \omega_{\mathrm{AA}}\right)}{\partial \mathrm{T}}=0.23$

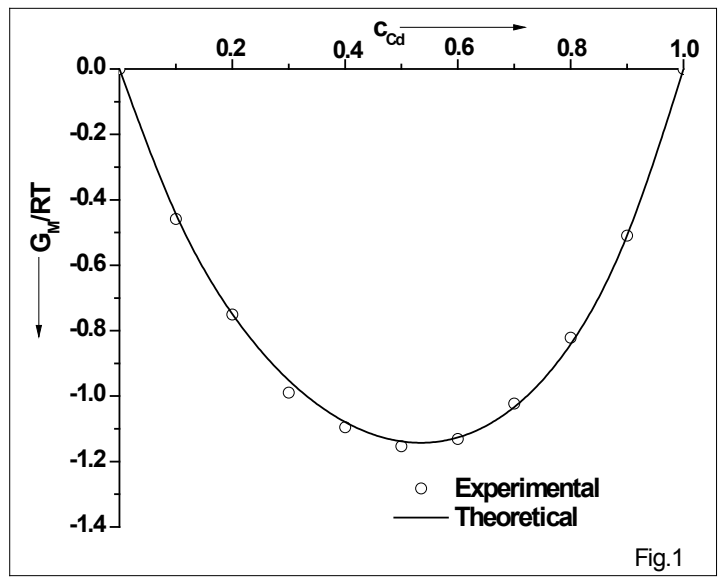

Figure 1. Free energy of mixing $\left(\mathrm{G}_{\mathrm{M}}\right) \mathrm{Vs}$ concentration of $\mathrm{Cd}\left(\mathrm{c}_{\mathrm{Cd}}\right)$ in liquid $\mathrm{Cd}-\mathrm{Hg}$ alloy at $600 \mathrm{~K}$.
Heat of mixing $\left(\mathrm{H}_{\mathrm{M}}\right)$ for liquid $\mathrm{Cd}-\mathrm{Hg}$ alloys at $600 \mathrm{~K}$ is computed by using eq.(4). The graph is plotted for heat of mixing with both theoretical and experimental values against concentration of cadmium, which is shown in fig.(2). The figure shows that theoretical values of $\mathrm{H}_{\mathrm{M}}$ are in good agreement along with the experimental values [Hultgren et al.,1973] in the whole range of concentration of $\mathrm{Cd}$. The heat of mixing for $\mathrm{Cd}-\mathrm{Hg}$ alloy in liquid state is negative in whole composition with minimum of $-0.52406 \mathrm{RT}$ at $\mathrm{c}_{\mathrm{Cd}}=0.5$, which is very close to experimental value $(-0.52587 \mathrm{RT})$ at the same concentration of $\mathrm{Cd}$. The contribution from the formation of complex on the heat of mixing is maximum at $\mathrm{c}_{\mathrm{Cd}}=0.66$, while the contribution from mixing terms is the greatest around $\mathrm{c}_{\mathrm{Cd}}=$ 0.5 .

\subsection{Entropy of mixing}

Using equation (5) along with eq.(3) and (4), entropy of mixing $\left(\mathrm{S}_{\mathrm{M}}\right)$ for liquid $\mathrm{Cd}$ $\mathrm{Hg}$ alloys is computed. For the theoretical calculation of $\mathrm{S}_{\mathrm{M}}$, same energy parameters (Eq.

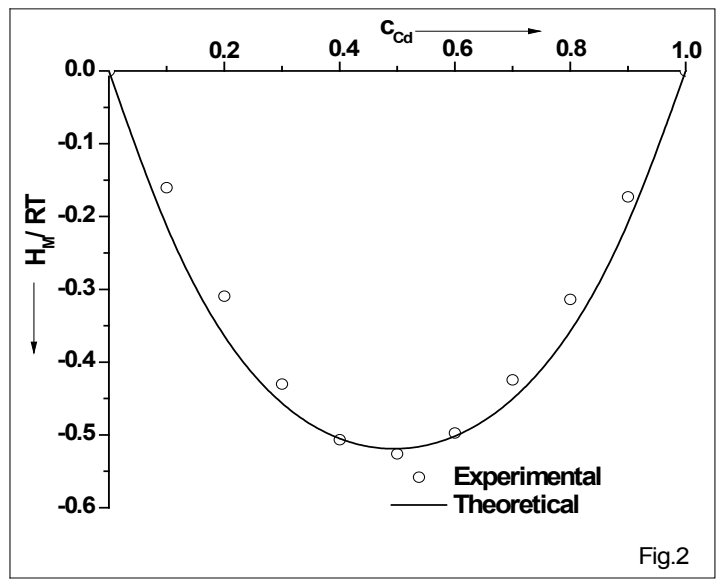

Figure 2. Heat of mixing $\left(\mathrm{H}_{\mathrm{M}}\right) \mathrm{Vs}$ concentration of $\mathrm{Cd}\left(\mathrm{c}_{\mathrm{Cd}}\right)$ in liquid $\mathrm{Cd}-\mathrm{Hg}$ alloy at $600 \mathrm{~K}$. 
(12) and (13) ) are used. The plot of entropy of mixing $\left(\mathrm{S}_{\mathrm{M}}\right)$ verses concentration of $\mathrm{Cd}$ is depicted in fig.(3),for both the computed and observed values. It is also observed that concentration dependence of asymmetry in $\mathrm{S}_{\mathrm{M}}$ can be explained only when one considers the temperature dependence of the pair-wise interaction energies. The computed values of $\mathrm{S}_{\mathrm{M}}$ are in very good agreement with experiment values. The theoretical and experimental both values of $\mathrm{S}_{\mathrm{M}}$ are positive in whole range of concentration of cadmium. The computed result indicates that $\mathrm{Cd}-\mathrm{Hg}$ alloy in liquid state is more ordered in higher concentration of $\mathrm{Cd}$.

\subsection{Chemical activity}

The deviations from ideal behavior of the alloys can be incorporated into activities. The pair of equations (7) and (8) is used for theoretical calculation of chemical activity of the constituent atom in $\mathrm{Cd}-\mathrm{Hg}$ alloys. Figure (4) shows the comparison between computed and observed values of chemical activity of the species of Cd-Hg alloys. There is good

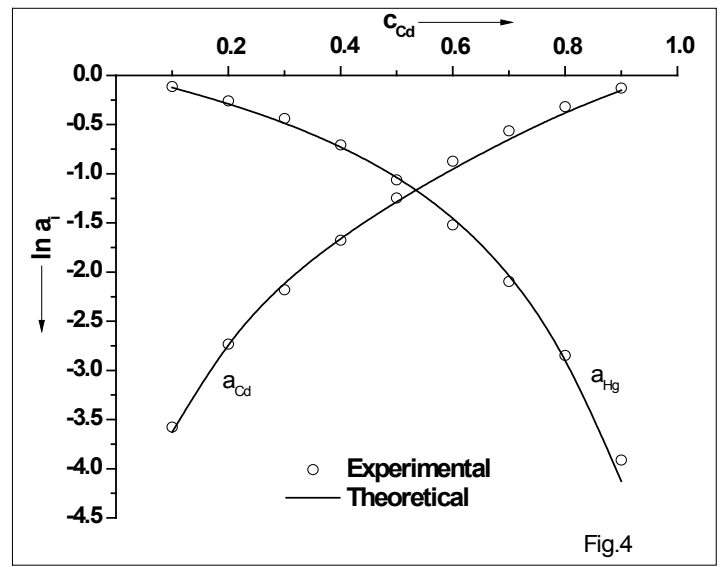

Figure 3. Entropy of mixing $\left(\mathrm{S}_{\mathrm{M}}\right) \mathrm{Vs}$ concentration of $\mathrm{Cd}\left(\mathrm{c}_{\mathrm{Cd}}\right)$ in liquid $\mathrm{Cd}-\mathrm{Hg}$ alloy at $600 \mathrm{~K}$. agreement between the computed and observed values of activity of $\mathrm{Cd}$ and $\mathrm{Hg}$ in $\mathrm{Cd}-\mathrm{Hg}$ system at $600 \mathrm{~K}$ at all concentration of $\mathrm{Cd}$. The agreement between theory and experiment for the both components is comparatively better in lower concentration of $\mathrm{Cd}$.

\subsection{The concentration-concentration fluctuation in long wavelength limit and Warren-Cowley short range order parameter:}

The Concentration fluctuations in the long-wavelength limit $\left(\mathrm{S}_{c c}(0)\right)$ is an essential structural function which has been widely used to study the nature of atomic order in binary liquid alloys [Bhatia \& Thronton, 1970]. There are difficulties in diffraction experiment, therefore theoretical determination of $\mathrm{S}_{\mathrm{cc}}(0)$ is of great importance when nature of interactions in the melt has to be analyzed. The mixing behavior of liquid alloys can be deduced from the deviation of $\mathrm{S}_{\mathrm{cc}}(0)$ from $\mathrm{S}_{\mathrm{cc}}^{\mathrm{id}}(0)$. At a given composition if $\mathrm{S}_{\mathfrak{c}}(0)<\mathrm{S}_{\mathfrak{c}}^{\text {dd }}(0)$, ordering in liquid alloy is expected while $S_{\mathbf{c}}(0)>S_{\mathbf{c}}^{\text {d }}(0)$

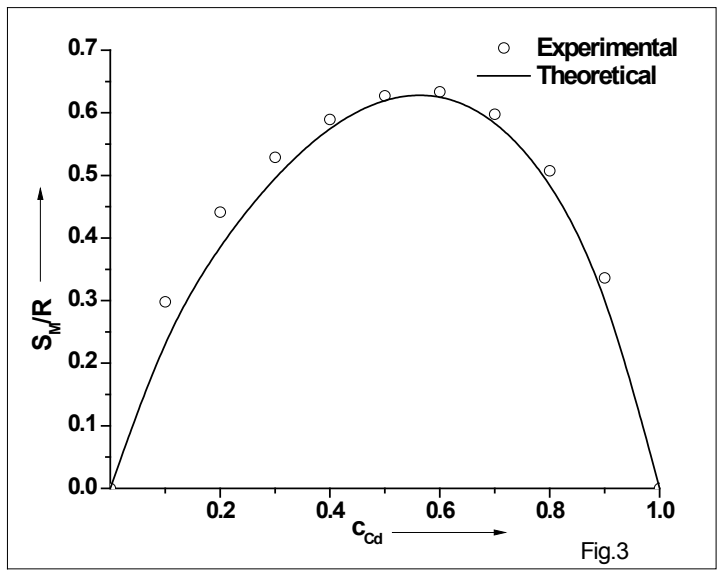

Figure 4. Chemical activity $\left(a_{i}\right)$ Vs concentration of $\mathrm{Cd}\left(\mathrm{c}_{\mathrm{Cd}}\right)$ in liquid Cd-Hg alloy at $600 \mathrm{~K}$. 
gives the indication of tendency of segregation. $\mathrm{S}_{\mathrm{cc}}(0)$ can also be obtained directly from the measured activity[Bhatia \& Hargoov, 1974] data as

$$
\mathrm{S}_{\mathrm{cc}}(0)=(1-\mathrm{c}) \mathrm{a}_{\mathrm{A}}\left(\frac{\partial \mathrm{a}_{\mathrm{A}}}{\partial \mathrm{c}}\right)_{\mathrm{T}, \mathrm{P}, \mathrm{N}}^{-1}=\mathrm{ca} \mathrm{a}_{\mathrm{B}}\left(\frac{\partial \mathrm{a}_{\mathrm{B}}}{\partial(1-\mathrm{c})}\right)_{\mathrm{T}, \mathrm{P}, \mathrm{N}}^{-1}
$$

where $a_{A}$ and $a_{B}$ are the observed chemical activities of the component atom respectively. The $\mathrm{S}_{\mathrm{cc}}(0)$, obtained from Eq.(14) are taken as experimental values.

The Warren-Cowley [Warren, 1969; Cowley,1950] short-range order parameter $\left(\alpha_{1}\right)$ is useful parameter to quantify the degree of chemical order in th alloy melt. It provides insight into the local arrangement of the atoms in the molten alloys. For the equi-atomic composition, the chemical short range order parameter is found to be $-1 \leq \alpha_{1} \leq 1$. Negative values of $\alpha_{1}$ indicate ordering in the melt, which is complete if $\alpha_{1}=-1$. On the other hand, positive values of $\alpha_{1}$ indicate segregation, leading to complete only if $\alpha_{1}=1$. But $\alpha_{1}=0$, corresponds to random distribution of the atoms in the mixture.

The $\mathrm{S}_{\mathrm{cc}}(0)$ and $\alpha_{1}$ have been computed as a function of concentration of Cd using Eqs.(9) and (11) respectively. The plot of theoretical, experimental and ideal values of $\mathrm{S}_{c c}(0)$ and theoretical value of $\alpha_{1}$ are displayed in fig.5. The computed values for $\mathrm{S}_{\mathrm{cc}}(0)$ shows good agreement with the experimental values. Our theoretical analysis shows that computed values of $\mathrm{S}_{\mathrm{cc}}(0)$ are lesser than the ideal values at all concentration range of $\mathrm{Cd}$. We have found that the deviation of $\mathrm{S}_{\mathrm{cc}}(0)$ from ideal value is maximum $(0.113)$ at $\mathrm{c}_{\mathrm{Cd}}=0.61$, which

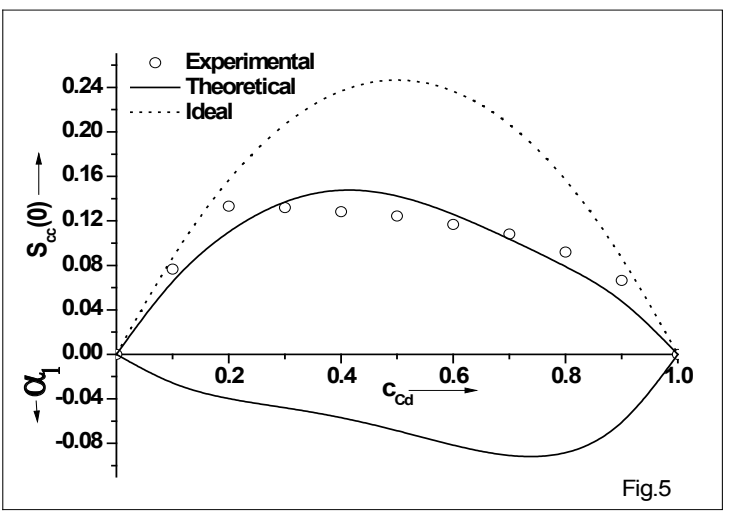

Figure 5. Concentration fluctuation at long wavelength limit $\left(\mathrm{S}_{\mathrm{cc}}(0)\right)$ and short range order parameter $\left(\alpha_{1}\right)$ Vs concentration of cadmium $\left(\mathrm{C}_{\mathrm{Cd}}\right)$ in liquid $\mathrm{Cd}-\mathrm{Hg}$ alloy at $600 \mathrm{~K}$.

is close to stoichiometric composition, $\mathrm{c}_{\mathrm{Cd}}$ $=0.67$. Fig. 5 also shows that $\alpha_{1}$ are negative throughout all concentration, showing $\mathrm{Cd}-\mathrm{Hg}$ is ordering system of unlike atoms pairing at all compositions. There is maximum depth near the compound forming composition. The asymmetry in $\alpha_{1}$ is distinctly observed.

\section{Conclusions}

The presented theoretical model successfully explains the observed concentration dependent asymmetries reproduced by considering the existence of chemical complexes $\mathrm{Cd}_{2} \mathrm{Hg}$ in molten phase. The analysis suggests that the tendency of hetero-coordination of atom depends very much on concentration and the $\mathrm{Cd}-\mathrm{Hg}$ system is moderately interacting. The analysis also reveals that most of the energy parameters depend considerably on temperature.

\section{Acknowledgments}

Editor N. P. Chapagain thanks the reviewers for their assistance in evaluating this paper. 


\section{References}

Akinlade, O., Singh, R.N.(2002), Bulk and surface properties of liquid $\mathrm{In}-\mathrm{Cu}$ alloys. J.Alloys and Compounds, 333, 84.

Anusionwu, B.C., Akinlade, O., Hussain, L.A. (1998), Assessment of size effect on the surface properties of some binary liquid alloys, J.Alloys compounds, 278, 175.

Bhatia, A. B. and Thornton, D. E.(1970), Structural Aspects of the Electrical Resistivity of Binary Alloys, Phys. Rev. B, 8:2,3004-3012.

Bhatia, A.B., Hargoove, W.H.(1974), Concentration fluctuation and thermodynamic properties of some compound forming binary liquid alloys, Phys. Rev.B., 10, 3186.

Bhatia, A.B., Singh, R.N.( 1982), Short range order and concentration fluctuations in regular and compound forming molten alloys, Phys. Chem. Liq., 11, 343.

Cowley, J.M.(1950), Phys. Rev.,77, 667.

Guggenheim, E.A.(1952), Mixture, Oxford University Press, London.

Hultgren, R., Desai, P.D., Hawkins, D.T., Gleiser, M., Kelley, K.K. (1973), Selected Values the of Thermodynamic Properties of Binary Alloys, ASM Metals Park, Ohio,1013.

Jha, I.S., Koirala,I., Singh, B.P.,Adhikari,D.(2014),
Concentration dependent thermodynamic, transport and surface properties in $\mathrm{Ag}-\mathrm{Cu}$ liquid alloys Applied Physics A, 116(3), 1517-1523.

Koirala,I., Singh, B.P., Jha, I.S. (2014), Theoretical assessment on segregating nature of liquid In-Tl alloys, J. Non-Cryst.Solids 398, 26-31.

Novakovic, R.( 2010), Thermodynamics, surface properties and microscopic functions of liquid $\mathrm{Al}-\mathrm{Nb}$ and $\mathrm{Nb}-\mathrm{Ti}$ alloys, J.Non-Cryst.Solids, 356, 1593.

Prasad, L.C., Singh, R.N.(1991) Surface segregation and concentration fluctuations at the liquid vapor interface of molten Cu-Ni alloys, Phys.Rev.B, 44, 13768.

Prasad, L.C., Singh, R.N., Singh, V.N., Singh, G.P.(1998), Correlation between bulk and surface properties of Ag-Sn liquid alloys, J.Phys. Chem. B,102, 921.

Singh, R.N., Mishra, I.K., Singh, V.N.(1990), Local order in Cd-based liquid alloys, Phys.Condens. Matter, 2, 8457.

Singh, R.N., Sommer, F.(1992), Temperature dependence of thermodynamic functions of strongly interacting liquid alloys, J. Phys. Condens.Matter, 4, 5345.

Warren B.E.(1969), X-ray Diffraction. AddisonWesle, Reading MA., 227. 